\title{
Neuroimmune semaphorin 4A downregulates the severity of allergic response
}

\author{
EH Nkyimbeng-Takwi ${ }^{1,2}$, K Shanks ${ }^{1}$, E Smith $^{1}$, A Iyer $^{1}$, MM Lipsky $^{3}$, LJ DeTolla $^{3}$, H Kikutani $^{4}$, \\ AD Keegan ${ }^{1,2,5}$ and SP Chapoval ${ }^{1,2,5}$
}

To define the role of semaphorin 4A (Sema4A) in allergic response, we employed Sema4A-/- and wild-type (WT) mice in the experimental model of ovalbumin (OVA)-induced allergic airway inflammation. We observed a selective increase in eosinophilic airway infiltration accompanied by bronchial epithelial cell hyperplasia in allergen-treated Sema4A ${ }^{-/-}$mice relative to WT mice. This enhanced inflammatory response was associated with a selective increase in bronchoalveolar lavage (BAL) interleukin 13 (IL-13) content, augmented airway hyperreactivity, and lower regulatory T cell (Treg) numbers. In vivo allergen-primed Sema4A ${ }^{-/-}$CD4 + T cells were more effective in transferring T helper type 2 (Th2) response to naive mice as compared with WT CD4 + T cells. T-cell proliferation and IL-13 productions in OVA $323-339$-restimulated Sema $4 A^{-/-}$cell cultures were upregulated. Generated bone marrow chimeras showed an equal importance of both lung-resident cell and inflammatory cell Sema4A expression in optimal disease regulation. These data provide a new insight into Sema4A biology and define Sema4A as an important regulator of Th2-driven lung pathophysiology.

\section{INTRODUCTION}

The incidence of asthma is on the rise worldwide, resulting in the increased morbidity and mortality and making it an economic burden to society. ${ }^{1,2}$ The pathophysiology of asthma is characterized by eosinophil-rich inflammatory cell infiltrates, mucus hypersecretion, airway hyperresponsiveness, and airway wall remodeling. ${ }^{3,4}$ Despite a number of currently used therapies such as glucocorticoids, $\beta$-agonists, antihistamines, phosphodiesterase inhibitors, and anticholinergic agents, many patients continue to suffer from the disease exacerbation. Moreover, many side effects of these medicines, which involve bone, metabolic, and cardiovascular systems, also limit their efficacy. 5,6 Therefore, novel molecular targets are being investigated ${ }^{7}$ and novel approaches are being developed ${ }^{8}$ that may have a profound impact on improving the diagnostic, prevention, and treatment of the allergic asthmatic diseases.

Semaphorin 4A (Sema4A) belongs to a large family of secreted and membrane-bound glycoproteins that were originally found to be expressed in the nervous system and function as axon guidance molecules. ${ }^{9}$ Recently, Sema $4 \mathrm{~A}$ was located in the lymphoid tissues where its expression was preferentially restricted to the antigen-presenting cells (APCs) such as dendritic cells (DCs) and $\mathrm{B}$ cells. ${ }^{10}$ It was reported to act as a costimulatory molecule, enhancing the activation and differentiation of $\mathrm{T}$ cells in vitro and potentiating the generation of antigen $(\mathrm{Ag})$-specific $\mathrm{T}$ cells in vivo. ${ }^{10,11}$ Sema4A functionally interacts with Tim-2 (T-cell immunoglobulin and mucin domain 2) expressed on T cells, Thelper type 2 (Th2) cells predominantly. ${ }^{10,11}$ In nonlymphoid tissues, Sema4A functionally interacts with plexin family members, namely Plexin D1 and Plexin B1. ${ }^{12-14}$ These interactions have been shown to play important roles in several physiological and pathological conditions such as angiogenesis, ${ }^{14}$ neuron growth cone collapse, ${ }^{13}$ and retina formation. ${ }^{12}$

In vitro, Sema $4 \mathrm{~A}-\mathrm{Fc}$ has been reported to enhance T-cell activation, proliferation, and interleukin 2 (IL-2) production, whereas anti-Sema4 A antibody $(\mathrm{Ab})$ inhibited allogeneic T-cell/DC mixed lymphocyte reaction. ${ }^{10}$ Mice with a targeted disruption of Sema4A developed normally but showed defects in the DC-mediated T-cell response. ${ }^{15}$ Whereas Sema4A ${ }^{-1-}$ DCs matured and responded normally to lipopolysaccharide or agonistic anti-CD40 $\mathrm{Ab}$ in vitro, the in vivo production of $\mathrm{Ag}$ specific $\mathrm{T}$ cells and cytokines was downregulated in Sema $4 \mathrm{~A}^{-1-}$

\footnotetext{
${ }^{1}$ Center for Vascular and Inflammatory Diseases, University of Maryland School of Medicine, Baltimore, Maryland, USA. ${ }^{2}$ Department of Microbiology and Immunology, University of Maryland School of Medicine, Baltimore, Maryland, USA. ${ }^{3}$ Department of Pathology, University of Maryland School of Medicine, Baltimore, Maryland, USA. ${ }^{4}$ Department of Molecular Immunology, Osaka University, Osaka, Japan. ${ }^{5}$ Program in Oncology, Greenebaum Cancer Center, University of Maryland School of Medicine, Baltimore, Maryland, USA. Correspondence: SP Chapoval (schapoval@som.umaryland.edu) 
mice after challenge with various Ags. ${ }^{15}$ Mice deficient in one of Sema4A functional receptors, Tim-2, exhibited increased lung inflammation and Th2 cytokine production in response to allergen. ${ }^{16}$ Based on all of the above, we hypothesized that Sema4A may have a critical nonredundant regulatory role in allergic asthma.

In this research, using the experimental model of allergeninduced asthma, we show that Sema4A downregulates the severity of allergic airway response. Ovalbumin (OVA)-challenged Sema $4 \mathrm{~A}^{-1-}$ mice showed an increased number of bronchoalveolar lavage (BAL) eosinophils and a wider spread of multiple inflammatory sites in the airways as compared with similarly treated wild-type (WT) mice. In addition, employing bone marrow (BM) chimeric mice, we demonstrate that Sema4A expression by lungresident cells as well as by inflammatory cells is critically important for the regulation of the disease severity. Using the in vivo cell transfer technique, we show here that allergen-primed spleenderived Sema $4 \mathrm{~A}^{-1-} \mathrm{CD} 4+\mathrm{T}$ cells are equally effective in either WT or Sema $4 \mathrm{~A}^{-1-}$ host to induce the substantial lung infiltration with eosinophils in response to OVA challenges, whereas WT $\mathrm{CD} 4+\mathrm{T}$ cells were much less efficient. This could be explained, in part, by a lower number of regulatory $\mathrm{T}$ cells (Tregs) found in Sema $4 \mathrm{~A}^{-1-}$ mice in addition to their higher local and systemic IL13 response to allergen. Our findings establish the cellular mechanisms of Sema4A function in the allergic response regulation and its potential as a novel therapeutic agent for asthma.

\section{RESULTS}

\section{Sema4A downregulates allergic airway response}

Although the role of Sema4A in experimental myocarditis ${ }^{17}$ and experimental autoimmune encephalomyelitis ${ }^{10}$ was established previously, its regulation of a Th2 response has not been investigated. Therefore, to detail Sema4A function in the allergic response, WT and Sema $4 \mathrm{~A}^{-1-}$ mice were subjected to the allergen priming, boost, and challenges as depicted in Figure 1a. Control mice were treated with Alum alone and nebulized with phosphate-buffered saline (PBS). A classical allergic airway response was observed in WT mice after OVA treatment

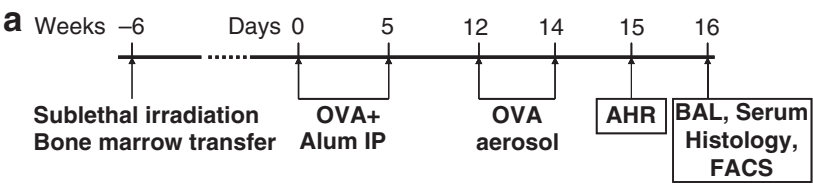

b

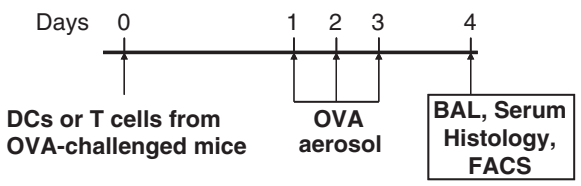

Figure 1 Experimental protocols used in this study. (a) Experimental protocols of the allergen treatment and (b) the in vivo adoptive cell transfer followed by antigen $(\mathrm{Ag})$ nebulizations. Models are detailed in the Methods section. AHR, airway hyperreactivity; BAL, bronchoalveolar lavage; DC, dendritic cell; FACS, fluorescence-activated cell sorting; OVA, ovalbumin.

(Figure 2a,b). This response consisted of prominent BAL and airway eosinophilic infiltration where $>50 \%$ of BAL cells were eosinophils (Figure 2a). Eosinophils were also the predominant cells in the lung tissue multiple peribronchial and perivascular inflammatory infiltrates (Figure 2b). Allergic inflammatory response was accompanied by mucus hypersecretion (Figure 2c). All these features of allergic response were significantly upregulated in Sema4 $\mathrm{A}^{-1-}$ mice (Figure 2a,c).

Sema4 deficiency was associated with higher serum levels of allergen-specific IgG1 and IgG2b, but not IgG2a (Figure 2d and data not shown). No significant differences in the total serum IgE levels between OVA-treated WT and Sema4A ${ }^{-1-}$ mice were found $\left(648.0 \pm 89.2\right.$ and $714.6 \pm 130.7 \mathrm{ng} \mathrm{ml}^{-1}$, respectively), whereas OVA-specific IgE concentrations differed significantly (409.2 \pm 81.4 and $725.0 \pm 89.9 \mathrm{ng} \mathrm{ml}^{-1}$, respectively, $P<0.01$ ). It is noteworthy that the levels of total IgE and OVA-specific IgE were measured in the sera samples obtained in separate in vivo experiments ( $n=4-5$ mice per experiment).

It is well known that allergic asthma is a Th2-driven disease where Th 2 cytokines play critical roles in the disease induction and exacerbation. ${ }^{18,19}$ To evaluate a possible local lung cytokine

Figure 2 Semaphorin 4A (Sema4A) deficiency increases the severity of allergic airway response in mice. (a) Wild-type (WT) and Sema4A-/mice were immunized with ovalbumin (OVA). Control mice were challenged with phosphate-buffered saline (PBS). (a) The average numbers $(n=3-5)$ of bronchoalveolar lavage (BAL) total cells (white bars) macrophages (black bars), eosinophils (forward hatched bars), lymphocytes (reverse hatched bars), and neutrophils (gray bars) \pm s.e.m. in one of three representative experiments are shown. ${ }^{*} \#<<0.05$, differences in absolute numbers of total cells and eosinophils in BAL between OVA-challenged WT and Sema4A ${ }^{-1-}$ mice. (b) Lung tissue sections were stained with hematoxylin and eosin (H\&E) for inflammation and (c) periodic acid-Schiff stain (PAS) for mucous cell hyperplasia evaluation. Magnification used for pictures is $\times 40$ and for inserts is $\times 100$. (d) Anti-OVA specific IgG antibodies (Abs) in serum samples ( $n=4$ mice per group) were measured using corresponding enzyme-linked immunosorbent assay (ELISA) kits as described in the Methods. ${ }^{*} P<0.05$, OVA-treated WT vs. Sema4A ${ }^{-/-}$ mice. (e) The levels of cytokines in BAL fluids (BALFs) of OVA-challenged WT (open bars) and Sema4A ${ }^{-1-}$ (black bars) mice measured by either ELISA or protein array were combined. Data are shown as mean \pm s.e.m. ( $n=3-6$ mice). ${ }^{*} P<0.05$, OVA-challenged WT vs. Sema4A ${ }^{-/-}$mice. (f) For cytokine Cytometric Bead Array (CBA) in lung lysates and $5 \times$ concentrated BALF, data were acquired by BD FACS Calibur and shown are FlowJo-generated dot plots for individual proteins for an individual mouse in one of two representative experiments ( $n=2$ per group). For a numeric representation of cytokine concentration, CBA data were calculated using the BD CBA software. ${ }^{*} P<0.02$ and ${ }^{*} P<0.004$, monocyte chemotactic protein-1 (MCP-1) and interleukin (IL)-17A in WT vs. Sema4A-/- mice, respectively. (g) Airway reactivity is shown as the percent increase in PenH over a baseline ( $n=6-8$ mice per group in the separate 3 experiments). ${ }^{*} P<0.05$, OVA-treated WT mice vs. Sema4A-I- mice for the corresponding doses of methacholine. Forced oscillation measurements were done in anesthetized mice employing FlexiVent (SCIREQ) and airway resistance is graphed as $\mathrm{cm} \mathrm{H}_{2} \mathrm{O}^{-1} \mathrm{ml}^{-1} \mathrm{~s}^{-1}$ ( $n=2$ mice per group). IFN- $\gamma$, interferon- $\gamma$; TGF- $\beta$, transforming growth factor- $\beta$; TNF- $\alpha$, tumor necrosis factor- $\alpha$. 
dysregulation induced by the Sema4A deficiency, we compared the levels of Th1/Th2 cytokines in the BAL and lung lysates obtained from allergen-treated WT and Sema $4 \mathrm{~A}^{-1-}$ mice. As shown in Figure 2e, we found a selective increase in IL-13 levels in the BAL of Sema $4 \mathrm{~A}^{-1-}$ mice when compared with WT mice, whereas other Th2 cytokines (IL-4 and IL-5) were not affected by Sema4A deficiency. In addition to that, the increased
BAL levels of IL-12p40 were detected in allergen-challenged Sema $4 \mathrm{~A}^{-1-}$ mice. It is noteworthy that no substantial differences in the BAL contents of eotaxin, RANTES (Regulated upon Activation, Normal T-cell Expressed, and Secreted), macrophage inflammatory protein (MIP)- $1 \alpha$, MIP- $1 \beta$, and vascular endothelial growth factor were detected between WT and Sema $4 \mathrm{~A}^{-1-}$ mice (data not shown). a

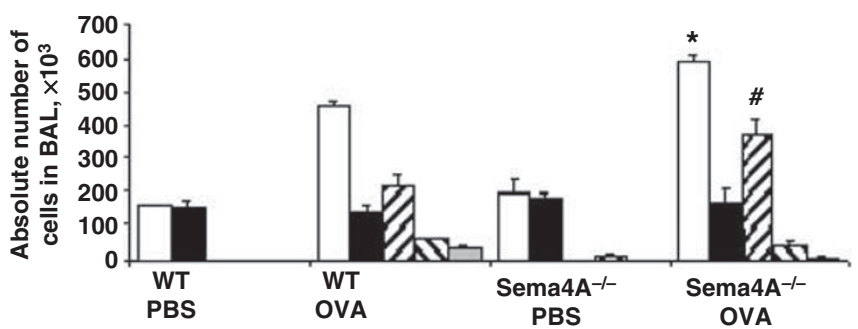

C
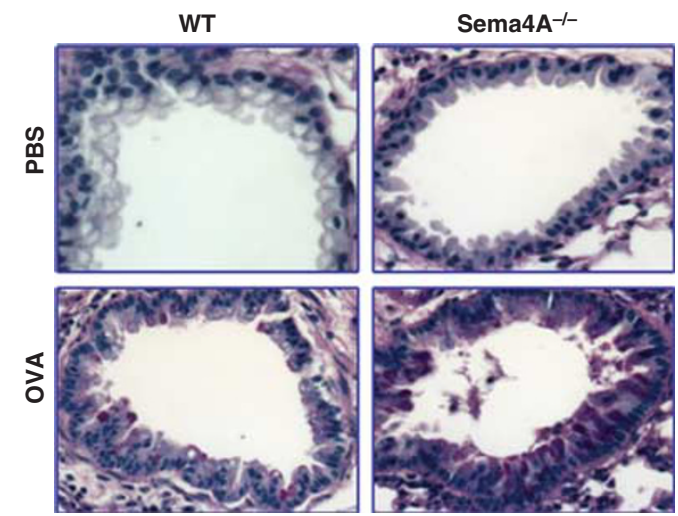

e
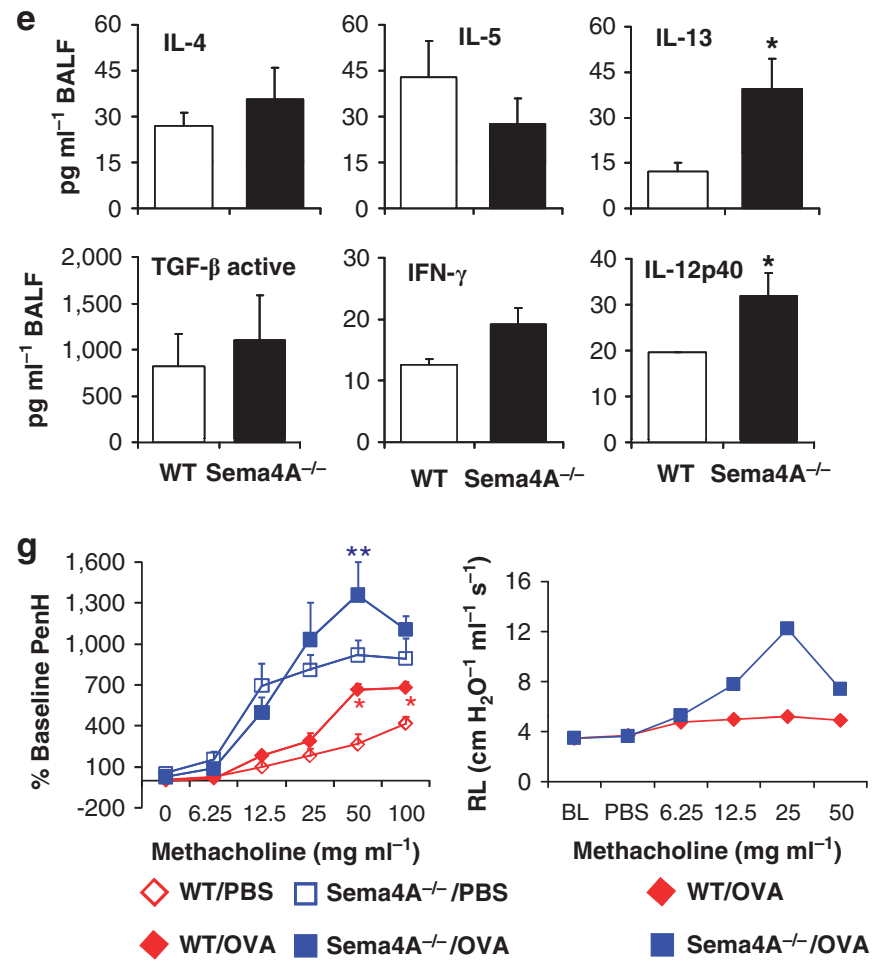

d

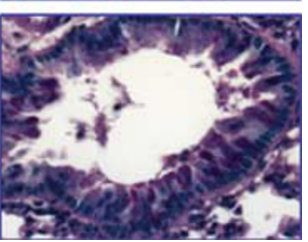

Methacholine $\left(\mathrm{mg} \mathrm{ml}^{-1}\right)$

$\diamond$ WT/PBS

Sema4A ${ }^{-1-} / \mathrm{PBS}$

WT/OVA Sema4A-1-/OVA

Sema4A-1-/OVA b
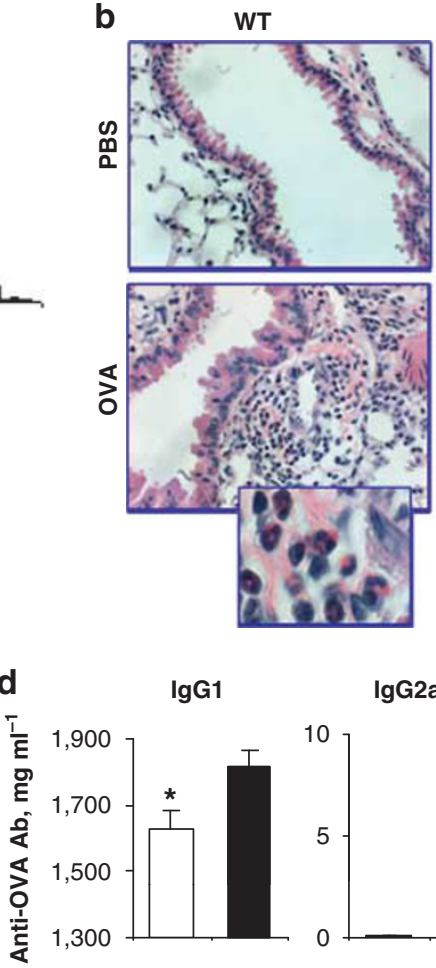

IgG2a

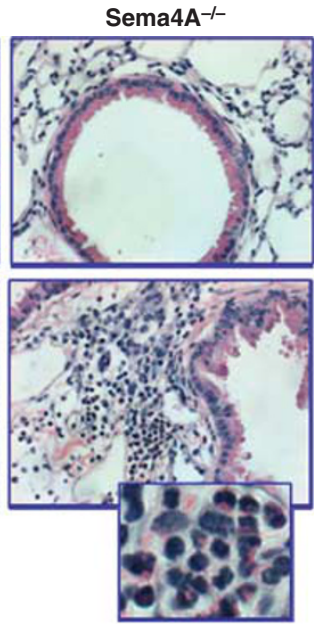

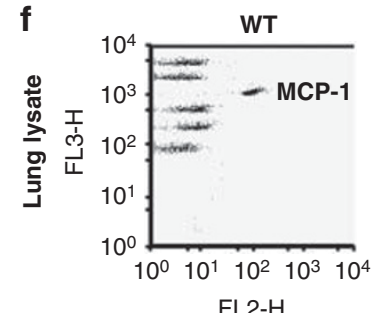
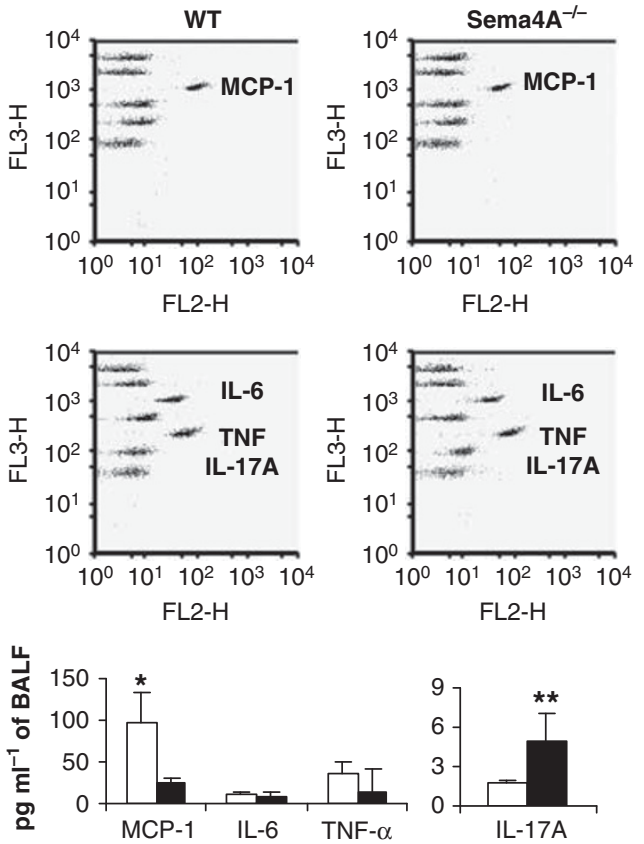
Proinflammatory cytokine Cytometric Bead Array (CBA) data showed decreased monocyte chemotactic protein-1 levels in the whole lung lysates and BAL fluid (BALF) obtained from OVA-treated Sema4A ${ }^{-1-}$ mice as compared with similarly treated WT mice (Figure 2f). It is noteworthy that lung lysates used in this analysis were equalized for the total protein content. In contrast, similar levels of tumor necrosis factor- $\alpha$ and IL- 6 measured with the CBA Th1/Th2/Th17 kit were found in the $5 \times$ concentrated BAL fluids obtained from both lines of OVAchallenged mice. Only IL-17A levels, although very low, were significantly increased in Sema $4 \mathrm{~A}^{-1-}$ mouse BALF.

To assess a direct effect of Sema4A on the airway physiology, we performed the airway hyperreactivity (AHR) measurements by a noninvasive technique (Figure $\mathbf{2 g}$ ). We found a significant augmentation in \% baseline $\mathrm{PenH}$, an index of airway obstruction, for four increasing doses of methacholine used (from 12.5 to $100 \mathrm{mg} \mathrm{ml}^{-1}$ ) in allergen-treated Sema4Amice as compared with similarly treated WT counterparts. The baseline PenH numbers differed significantly between OVAtreated experimental groups $(0.75 \pm 0.02$ vs. $0.92 \pm 0.03$, WT vs. Sema $4 \mathrm{~A}^{-1-}$ mice, respectively, $\left.P<0.0002\right)$, whereas no difference was observed with the lowest dose of methacholine for challenge. Surprisingly, we also found that PBS-challenged Sema $4 \mathrm{~A}^{-1-}$ mice have a significantly higher airway reactivity to methacholine challenges when compared with PBS-challenged WT mice. The results obtained employing an invasive lung AHR measurement technique correspond to those for the invasive lung function measurements (Figure 2g and data not shown).

As Sema4A deficiency obviously increases most measured features of an acute allergic response, we therefore concluded that Sema4A functions as a downregulatory molecule in the experimental model of allergic asthma.

\section{Both lung and BM Sema4A expression are critical for the downregulation of allergic asthmatic response}

We previously reported that in contrast to the lymphoid tissues, mouse lung tissue and cell Sema4A expression is generally low and is only slightly upregulated by allergen challenge. ${ }^{20,21}$ Therefore, our next set of experiments was aimed to determine if Sema4A expression by the lung-resident or BM-derived inflammatory cells is more critical for the regulation of the severity of allergic airway response.

We generated $\mathrm{BM}$ chimeras where irradiated WT or Sema $4 \mathrm{~A}^{-/-}$mice received BM from either WT or Sema4A $\mathrm{A}^{-/-}$ mice. These chimeric mice were then subjected to allergen treatment (Figure 1a). As expected and as shown in Figure 3a,b, OVA-challenged Sema $4 \mathrm{~A}^{-1-}$ mice that received Sema $4 \mathrm{~A}^{-1-}$ BM cells, namely Sema4A ${ }^{-1-}$ (donor (d)) - Sema $4 \mathrm{~A}^{-/-}$(recipient (r)), showed a robust allergic eosinophilic response in their $\mathrm{BAL}$ and lung tissues. Concurrently, we observed significantly lower levels of BAL eosinophilia in WT (d) - Sema4A-1- (r) mice and Sema4 $\mathrm{A}^{-1-}(\mathrm{d})-\mathrm{WT}(\mathrm{r})$ mice as compared with Sema $4 A^{-1-}$ (d) - Sema $4 A^{-1-}$ (r) mice $(120,900 \pm 1,900$ compared with $150,800 \pm 500$ and $352,500 \pm 1,400$ cells, respectively). WT (d) - WT (r) group demonstrated an increased number of BAL macrophages as compared with all other chimeric mice treated with allergen. Importantly, the level of eosinophilic infiltration into BAL in WT (d) - WT (r) chimeras was significantly lower than that observed in a positive control of this study, Sema4 $\mathrm{A}^{-1-}(\mathrm{d})-$ Sema $4 \mathrm{~A}^{-1-}(\mathrm{r})$ mice $(101,200 \pm 21,200$ cells vs. $352,500 \pm 1,400$ cells, respectively). In addition, eosinophilia in WT chimeras was lower as compared with the chimeric mice involving the absence of Sema4A expression either on structural or hematopoietic cells, which additionally supports the important regulatory role of Sema4A in the outcome of allergic lung inflammatory response. The lower density and size of allergen-induced infiltrates was also noted in the lung tissues of corresponding chimeric mice when compared with a positive control for this study, Sema $4 \mathrm{~A}^{-/-}(\mathrm{d})-\operatorname{Sema} 4 \mathrm{~A}^{-/-}(\mathrm{r})$ mice (Figure 3b). Acute inflammatory infiltrates in BM chimeric mice consisted predominantly of eosinophils, neutrophils, and lymphocytes associated mostly with perivascular and peribronchial areas. The periodic acid-Schiff (PAS) staining was the most prominent in Sema4A ${ }^{-1-}$ (d) - Sema4 $\mathrm{A}^{-1-}$ (r) mice where $>50 \%$ of bronchioles were PAS positive, whereas for other chimeric mice this number was not that remarkable, with only $2-3$ bronchial profiles per tissue displaying PAS positivity (Figure 3c). It is noteworthy that no such inflammation was found in the BAL (data not shown) and lungs (Figure 3b) of any chimeric mouse challenged with PBS. Therefore, both lung and $\mathrm{BM}$ Sema4A expression is equally critical for the allergic inflammatory response regulation. However, it is not equally efficient for the local lung cytokine response.

Cytokine content in $5 \times$ BALF was measured using CBA inflammatory cytokine (data not shown) and Th1/Th2/Th17 kits (Figure 3d). Consistent lower levels of IL-6 and tumor necrosis factor- $\alpha$ were detected in BALF of WT(d) -Sema $4 \mathrm{~A}^{-1-}(\mathrm{r})$ mice as compared with other chimeric counterparts. Interestingly, we observed the increased local IL-17A levels (Figure 3d) in both chimeric mice lacking Sema4A lung tissue expression.

\section{Sema4 $A^{-1-}$ CD $4+T$ cells are more effective in transferring allergic response than $W T$ CD4 + T cells}

In the lymphoid tissues, Sema4A is expressed on APCs, mainly on DCs, ${ }^{9,15,20,21}$ and function as a costimulator of T-cell activation. ${ }^{10,11}$ We found that lung tissue DCs did not show any measurable Sema4A cell surface expression in either steady-state or inflammatory condition. ${ }^{20,21}$ On the other hand, it is also known that Sema4A expression is induced on activated CD4+ T cells mainly of Th1 phenotype ${ }^{15}$ that might either downregulate $^{22}$ or potentiate ${ }^{23}$ the allergic inflammatory response. As reported above (Figure 2e,f), we did not find any significant differences in the BALF interferon- $\gamma$ contents between WT and Sema $4 \mathrm{~A}^{-1-}$ mice, suggesting that Sema $4 \mathrm{~A}$ deficiency does not affect the overall negligible Th1 response to allergen in this model. Based on all of the above, we next asked the question whether Sema4A expression by CD $4+\mathrm{T}$ cells or DCs is more critical for the regulation of the allergic response severity. For that purpose, we isolated DCs and CD4 + T cells from the lungs and spleens of allergen-challenged Sema $4 \mathrm{~A}^{-1-}$ mice and transferred them into naïve mice intranasally followed by three consecutive OVA nebulizations over a period of $72 \mathrm{~h}$ (Figure $\mathbf{1 b}$ ). 

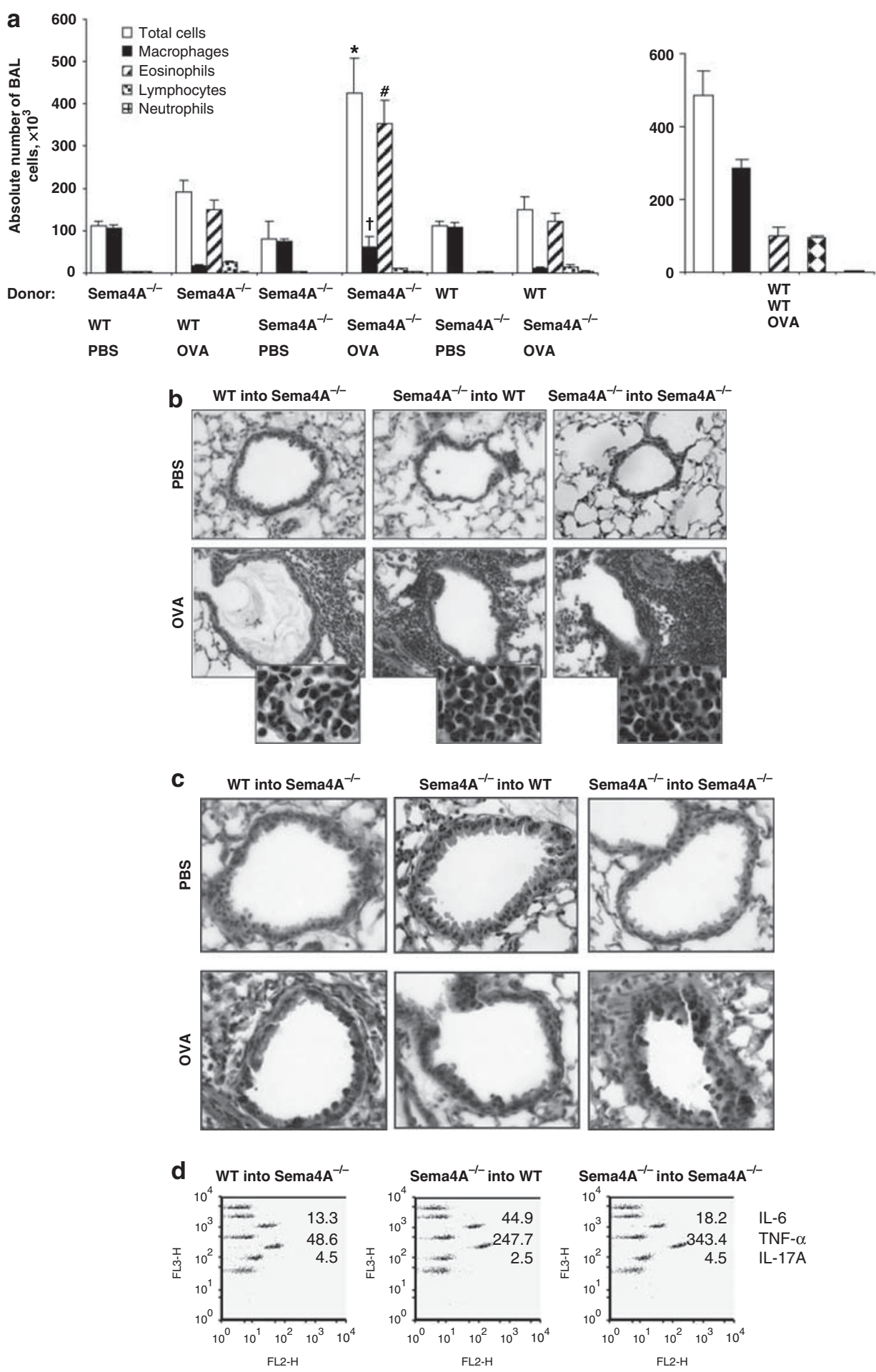

Figure 3 Semaphorin 4A (Sema4A) expression on bone marrow (BM)-derived cells and lung-resident cells is critical for the downregulation of allergic airway response. The indicated BM chimeras were generated as described in the Method. Nonirradiated wild-type (WT) mice and the chimeras were immunized with Alum or ovalbumin (OVA)/Alum and challenged as indicated. (a) Lungs were lavaged and the cells in the bronchoalveolar lavage (BAL) were analyzed by the differential counting. The average numbers of BAL total cells (white bars) macrophages (black bars), eosinophils (hatched bars), lymphocytes (dotted bars) and neutrophils (grid bars) \pm s.e.m. are shown ( $n=3-4$ mice per group). ${ }^{*}+$, $P<0.05$, differences in absolute numbers

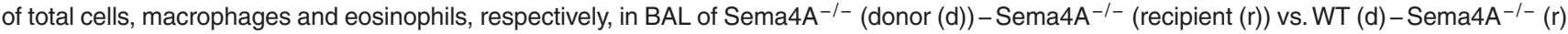
or Sema4A ${ }^{-/-}(d)-W T(r)$. WT (d) -WT (r) group was assessed in a separate experiment. (b) Representative lung histology (hematoxylin and eosin (H\&E), $\times 40$; inserts, $\times 100$ ) from phosphate-buffered saline (PBS)- and OVA-challenged mice is shown. (c) Representative periodic acid-Schiff stain (PAS) for mucous cell hyperplasia. Magnification used for pictures is $\times 40$. (d) Cytokine contents in concentrated BAL measured using a Cytometric Bead Array (CBA) Th1/Th2/Th17 kit. Data are shown as FlowJo-generated dot plots and CBA software-calculated cytokine concentrations for polled samples from two mice in one of two representative experiments. IL, interleukin; TNF- $\alpha$, tumor necrosis factor- $\alpha$. 


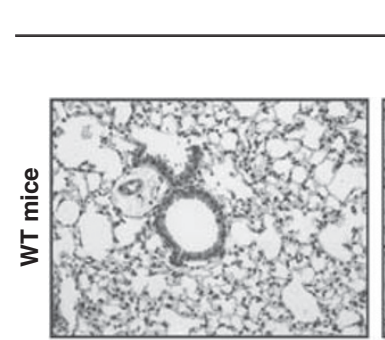

$0.7 \pm 0.3 \%$

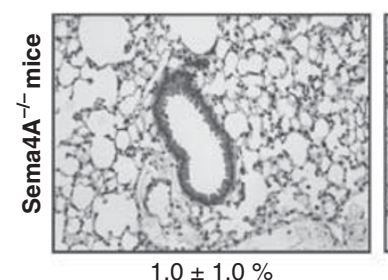

$1.0 \pm 1.0 \%$

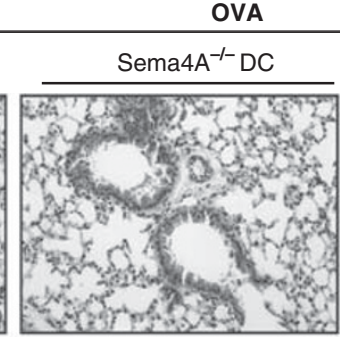

$0.7 \pm 0.3 \%$

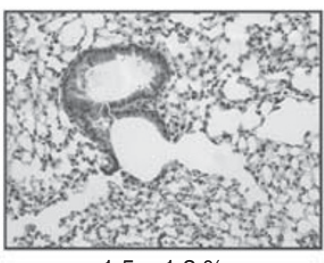

$1.5 \pm 1.3 \%$

WT DC

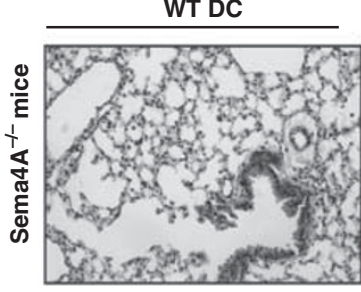

$1.4 \pm 0.7 \%$

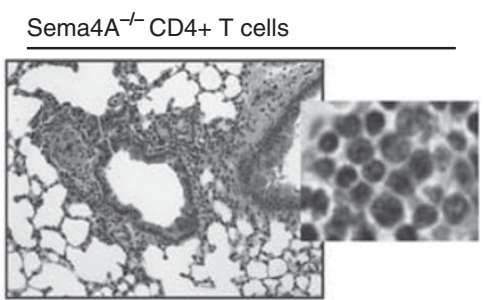

$20.0 \pm 5.6 \%$

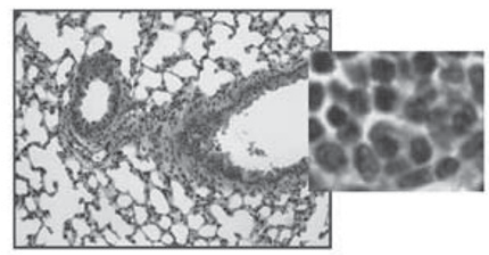

$24.8 \pm 10.4 \%$

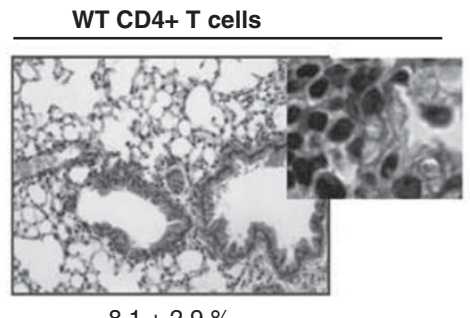

$8.1 \pm 2.9 \%$

Figure 4 CD4 + T cells but not dendritic cells (DCs) from ovalbumin (OVA)-challenged Sema4A-/- mice transfer allergic eosinophilic response to naive mice followed by allergen challenges. Mice that received either lung DCs (CD11c+CD11b + cells) or spleen CD4 + T cells obtained from either OVA-challenged wild-type (WT) or Sema4A $\mathrm{A}^{-/-}$mice were subjected to three consecutive allergen nebulizations and assessed for lung inflammatory response $24 \mathrm{~h}$ later $(n=3-5)$. Allergen-challenged mice that did not receive cell transfer served as controls. Note the inflammatory cell accumulations in the lung tissues of WT and Sema4A-1- mice after Sema4A-1- CD4 + T cell transfer followed by allergen nebulizations. Sema4A, semaphorin 4A.

We have found that Sema4A $\mathrm{A}^{-1-} \mathrm{CD} 4+\mathrm{T}$ cells but not DCs were able to induce a substantial allergic eosinophilic response in the cell-recipient WT and Sema4 $\mathrm{A}^{-1-}$ mice (Figure 4) upon in vivo Ag challenges. Moreover, Sema4A $\mathrm{A}^{-1-} \mathrm{CD} 4+\mathrm{T}$ cells were as effective in WT hosts as in Sema $4 \mathrm{~A}^{-/-}$hosts for the induction of eosinophilia after allergen challenge, as the relative numbers of BAL eosinophils were not different between the cell-recipient groups. At the same time, WT CD4 + T cells were not as efficient to transfer the allergic response as Sema4 $4 \mathrm{~A}^{-1-} \mathrm{CD} 4+$ $\mathrm{T}$ cells. Examination of histology slides demonstrated the presence of multifocal perivascular and peribronchial mono-lymphoeosinophilic infiltrates in the lungs of WT and Sema4 $\mathrm{A}^{-1-}$ mice that received adoptively transferred Sema $4 \mathrm{~A}^{-1-} \mathrm{CD} 4+$ T cells.

\section{The downregulatory effect of Sema4A on allergic airway inflammation is associated with increased Treg numbers}

Considering an emerging critical role of Tregs in the Th2 response suppression, ${ }^{22,23}$ we analyzed the numbers of Tregs in the lungs of WT and Sema4 $\mathrm{A}^{-1-}$ mice subjected to the allergen priming and challenges. For this flow cytometry analysis we employed corresponding Abs for the Treg detection (Figure 5a). We found significant differences in the relative and absolute numbers of lung Tregs between WT and
Sema $4 \mathrm{~A}^{-/-}$mice $(46.9-51.7 \%$ and $31.1-38.0 \%$ Foxp3 + cells among CD25 + CD4 + T cells, respectively). At the same time, the numbers of both CD8 + and CD4 + T cells in the OVAchallenged Sema $4 \mathrm{~A}^{-1-}$ mice as compared with similarly treated WT mice were increased in the lungs $(5.4 \pm 0.4$ and $8.1 \pm 0.5 \%$ compared with $2.4 \pm 0.5 \%$ and $6.1 \pm 0.2 \%$, respectively, $P<0.003$ and $P<0.006$ ) and spleens (Figure 5a,b), whereas spleen B-cell numbers were downregulated (Figure $\mathbf{5 b}$ ). This suggests that a defined increased inflammatory response in Sema $4 \mathrm{~A}^{-1-}$ mice is associated with increases of T-cell lung infiltration but a downregulation of Tregs.

\section{Sema4A deficiency upregulates the in vitro recall T-cell response to $\mathrm{OVA}_{323-339}$ peptide but not to OVA protein}

As Sema4A expression on APCs is reported to be a critical costimulator for Ag-specific T-cell activation, ${ }^{10}$ we analyzed the in vitro spleen mononuclear cell (MNC) response to OVA restimulation (Figure 6). Employing two distinct methods for T-cell proliferation measurement, we have found that a proliferative response to a whole OVA protein was not affected by Sema4A deficiency, whereas the response to $\mathrm{OVA}_{323-339}$ peptide was significantly upregulated (Figure 6a,b ). As Tim-2 is a reported functional Sema4A receptor on T cells, ${ }^{10}$ we concluded that Sema4A/Tim-2 interaction may play an important but not 
a
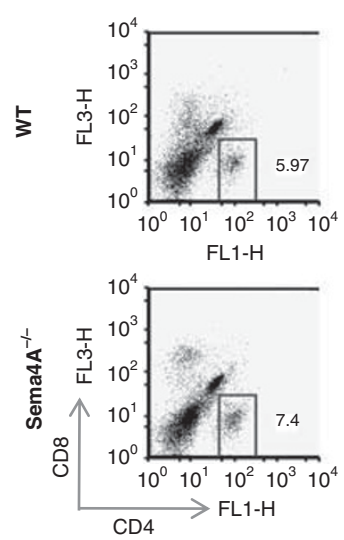

b
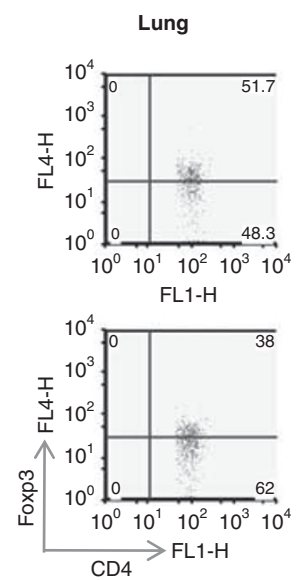

Spleen
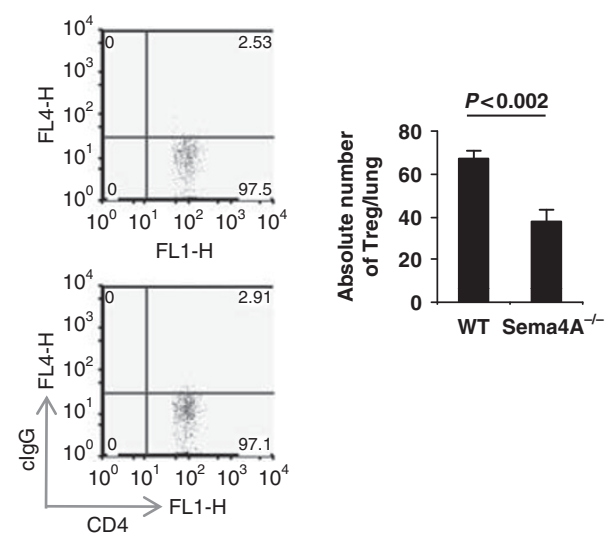
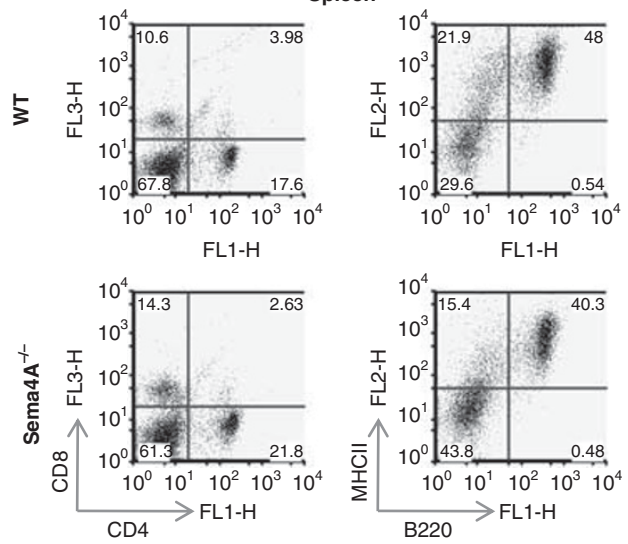

Figure 5 Increased T-cell and decreased regulatory T cell (Treg) numbers are associated with a heightened allergic response in Sema4A-1mice. (a, b) Wild-type (WT) and Sema4A-/- mice were immunized and challenged with ovalbumin (OVA). Lungs were digested with collagenaseDNAse and spleens were sterilely processed omitting a digestion step. Single-cell suspensions were analyzed by fluorescence-activated cell sorting (FACS) for the expression of CD4 and CD8 T-cell markers. (a) Gated CD4 + T cells were further analyzed for the expression of CD25 and Foxp3 and the relative number of CD4 + Foxp3 + cells was ascertained in comparison with a control rat IgG protein stain. (b) Spleen T- and B-cell relative numbers in one out of three representative independent experiments are shown. Sema4A, semaphorin 4A.

exclusive role in the downregulation of the in vivo response to allergen. This conclusion is based on the reported above observation that the in vitro $\mathrm{T}$-cell recalled response to a whole protein was not compromised by Sema4A deficiency, and on the results of our previous study showing that the specifics of the lung tissue Sema $4 \mathrm{~A}$ and its receptors peptide was affected by Sema $4 \mathrm{~A}$ deficiency. More prominent effect was found on Th2 cytokine (IL-5 and especially IL-13) production by $\mathrm{OVA}_{323-339^{-} \text {-restimu- }}$ lated spleen MNCs (Figure 6c). No significant differences in the cell culture supernatant levels of IL-4, interferon- $\gamma$, IL-6, and IL-10 were found between WT and Sema4A- ${ }^{-1-} \mathrm{OVA}_{323-339^{-}}$ restimulated spleen MNCs. The noted higher levels of IL-17A in Sema $4 \mathrm{~A}^{-1-}$ cultures (7.8 $\pm 1.8 \mathrm{vs} .4 .1 \pm 2.0 \mathrm{pg} \mathrm{ml}^{-1}$ in WT mice) were not statistically significant.

\section{DISCUSSION}

In this study we demonstrate that Sema4A, which initially was reported to act as a critical positive regulator of T-cell activation and function, plays a downregulatory role in allergic airway inflammatory response. Its absence in vivo in Sema $4 \mathrm{~A}^{-1-}$ mice upregulated many features of allergic response such as eosinophilic BAL and lung tissue infiltration, mucous cell hyperplasia, AHR to methacholine challenges, sera Ag-specific IgG1/ IgG2b/IgE contents, and IL-13 levels in BAL, sera, and cell cultures.

The latter is especially interesting as it is well known that IL13 is a critical Th2 cytokine for the induction and regulation of allergic response. ${ }^{24-28}$ When IL-13 was blocked systemically, it resulted in a complete reversal of the allergen-induced AHR and mucus overproduction in the mouse experimental model of asthma. ${ }^{24}$ However, this blockade did not affect significantly airway eosinophilia and sera OVA-specific IgE levels. Nevertheless, when IL-13 was blocked locally, allergen-induced pulmonary eosinophilia was significantly attenuated. ${ }^{25}$ Furthermore, the importance of IL-13 in the induction and regulation of airway eosinophilia was defined in the studies employing a recombinant IL-13 administration to the mice ${ }^{24,25}$ that alone, in IL-4R $\alpha$-dependent manner, was able to induce eosinophilic 

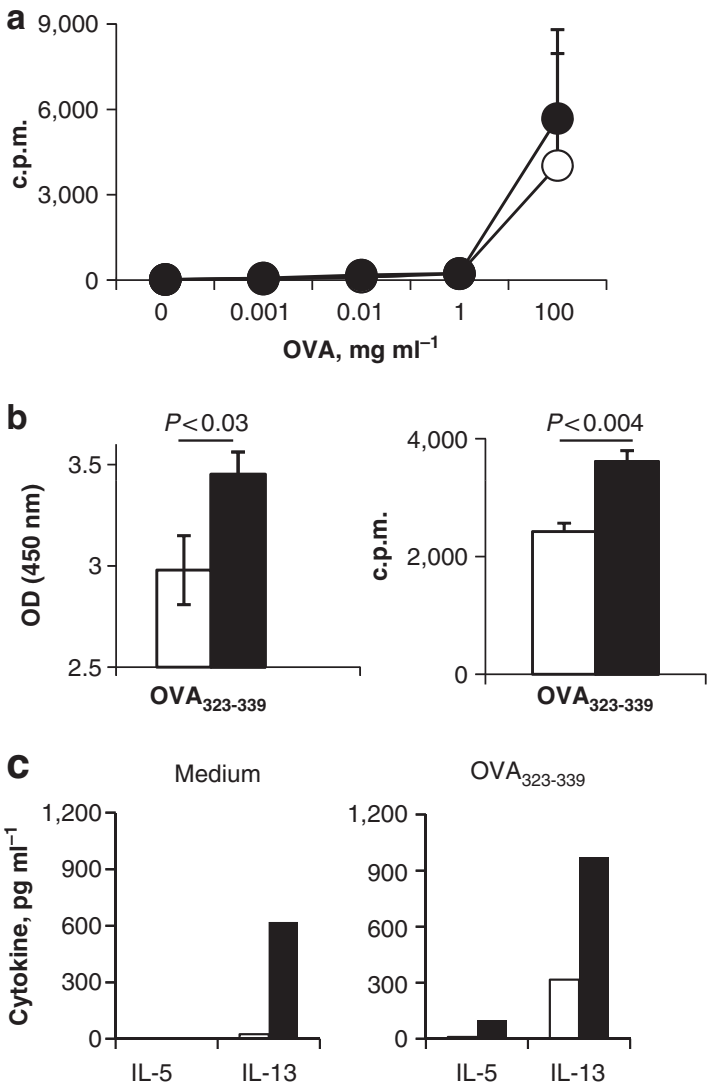

Figure 6 Semaphorin 4A (Sema4A) deficiency does not affect the in vitro recall $\mathrm{T}$-cell response to a whole allergen but upregulates the response to the $\mathrm{OVA}_{323-339}$ peptide challenge. (a-c) Spleen mononuclear cells (MNCs) were obtained from allergen-treated wildtype (WT; open circles or bars) and Sema4A ${ }^{-/-}$(black circles or bars) mice as described in the Methods. Cells were stimulated with either increasing doses of (a) ovalbumin (OVA) or (b, c) $200 \mu \mathrm{g} \mathrm{ml}^{-1}$ of $\mathrm{OVA}_{323-339}$ peptide for $72 \mathrm{~h}$. (a, b) Proliferation was measured in triplicate wells. $[\mathrm{H}]^{3}$ was added to the cultures for the last $24 \mathrm{~h}$ before cell harvest. Data are presented as mean c.p.m. \pm s.e.m. of $[\mathrm{H}]^{3}$ incorporation in $72 \mathrm{~h}$ cultures. (b) Means and s.e.m. are shown for the measured optical density (OD) of cells incubated with WST-1 solution for the colorimetric proliferation visualization. Means and s.e.m. of $[\mathrm{H}]^{3}$ incorporation in $72 \mathrm{~h}$ cultures. (c) Supernatants were taken at $72 \mathrm{~h}$ from the in vitro cell cultures restimulated with $\mathrm{OVA}_{323-339}$ peptide. Interleukin (IL)-5 and IL-13 contents are expressed as the average of corresponding cytokine concentration for two representative samples for each point.

infiltration and time-dependent increases in total sera IgE levels. ${ }^{26}$ Therefore, IL-13 alone is able to control a full asthmatic phenotype. Indeed, studies in IL-13 transgenic mice have demonstrated the IL-13-dependent MNC/eosinophil inflammation, AHR, and mucous cell metaplasia. ${ }^{27}$ We found a clear association of the increased lung local IL-13 levels and increased mucus secretions observed in OVA-challenged Sema $4 \mathrm{~A}^{-1-}$ mice as compared with WT mice (Figure 2c,d). The importance of IL-13 in the mucous cell hyperplasia was demonstrated in several previous studies that have shown that the mice lacking IL-13 [ref. 28] or IL-4R $\alpha$ (a common receptor subunit for IL-4 and IL-13[ref. 29]) or STAT6 (the IL-4R $\alpha$ signaling component ${ }^{30}$ ) lack goblet cell hyperplasia in response to $\mathrm{Ag}$ challenges.
Needless to say, the mechanism of IL-13 regulation by Sema4A remains to be determined.

Following OVA treatment, the Sema4A deficiency resulted in increased AHR in response to increasing doses of methacholine as compared with the similarly treated WT mice (Figure $\mathbf{2 g}$ ). Interestingly, PBS-treated Sema $4 \mathrm{~A}^{-/-}$mice show higher airway reactivity when compared with PBS-treated WT mice. We have shown previously that OVA treatment leads to the induction of Sema4A expression in the airway smooth muscle cells. ${ }^{20,21}$ Therefore, it might play some currently undefined role in the smooth muscle cell function. The lack of Sema4A may increase the sensitivity of the response of smooth muscle cells to an external pharmacological contractile stimulant such as methacholine, resulting in a higher airway reactivity that we observed in PBS-treated Sema4A $\mathrm{A}^{-1-}$ mice. ${ }^{31}$ The increased AHR in OVAtreated Sema $4 \mathrm{~A}^{-1-}$ mice might also be directly associated with increased local IL-13 levels. ${ }^{26,27}$

Sema4A deficiency is also associated with a systemic Th2 dysregulation (Figure 6c). Previous observation has shown the induction of Sema4A expression on activated Th1 cells and its necessity for the optimal in vitro Th1 generation and T-bet expression that significantly affected Th1/Th2 differentiation. ${ }^{15}$ At the same time, the in vivo Th1 cell response (interferon- $\gamma$ and IgG2b production) to Ag was downregulated in Sema $4 \mathrm{~A}^{-1-}$ mice, whereas Th 2 response (IL- 4 and IgG1 production) was not affected. It is noteworthy that we did not find any significant differences in interferon- $\gamma$ contents in BALF (Figure 2e,f) and Ag-restimulated spleen cell culture supernatants (data not shown) between Sema4 $\mathrm{A}^{-1-}$ and WT mice. Interestingly, we find increases in the sera OVA-specific Th2-dependent IgG1 and IgG2 $\mathrm{b}^{32}$ levels in allergen-treated Sema $4 \mathrm{~A}^{-1-}$ as compared with WT mice (Figure 2e). The seeming discrepancy in the results could be explained by the different immunization protocols and different adjuvants used. Indeed, Sema $4 \mathrm{~A}^{-1-}$ mice immunized with OVA in complete Freund's adjuvant CFA showed a substantially lower recall response in the delayed-type hypersensitivity model as compared with WT mice. ${ }^{15}$

Our study of the in vivo response of chimeric mice to allergen has shown that Sema4A on BM-derived inflammatory cells and on lung-resident cells is critically important for the allergic response regulation (Figure 3a). However, the AHR examination of chimeric mice demonstrated no differences between groups (data not shown), suggesting that the intensity of inflammatory response might dissociate with $\mathrm{AHR},{ }^{33}$ and that lung-resident cell Sema4A expression, airway smooth muscle cells in particular, ${ }^{20,21}$ most probably plays a protective role.

The especially interesting observation includes a low but significant increase of IL-17A in Sema $4 \mathrm{~A}^{-1-}$ mice in allergeninduced inflammation model (Figure 2f) and in chimeric mice lacking Sema4A on lung-resident cells (Figure 3d). The role of Th17 cytokines IL-17A and IL-17F in asthma has been a subject of numerous recent basic research and clinical studies. ${ }^{34-38}$ Recent studies in animal models have shown that the allergic sensitization through the airways but not through the peritoneum induced a strong Th17 response with AHR and lung neutrophilic but not 
eosinophilic inflammation. ${ }^{36}$ IL-17R deficiency downregulated the numbers of tissue-infiltrating neutrophils but upregulated eosinophil numbers in this model. The other study employing intraperitoneal OVA sensitization has shown that CD11b + F4/ $80+$ macrophages but not $\mathrm{T}$ cells in the airways of challenged mice were the major cellular source of IL-17. ${ }^{35}$ Interestingly, studies in human asthmatic patients have shown the increased numbers of IL-17 + cells in sputum and BAL in subjects with asthma as compared with control nonasthmatic subjects. ${ }^{34}$ Moreover, eosinophils were active producers of this cytokine that was also detected in a subset of sputum and BAL T cells. We did not find a significant difference in IL-17A levels in supernatants harvested from spleen MNC cultures with OVA peptide, although there was a trend for a higher concentration of this cytokine in Sema $4 \mathrm{~A}^{-/-}$ cell cultures. Based on all of the above, it is tempting to conclude that Sema4A regulates, either directly or indirectly, Th17 response to allergen systemically and in the lung.

We show that allergic response was equally efficient in both WT and Sema $4 \mathrm{~A}^{-1-}$ mice after Sema4A $\mathrm{A}^{-1-} \mathrm{CD} 4+\mathrm{T}$ cell transfer, whereas the in vivo Ag-primed lung Sema $4 \mathrm{~A}^{-1-} \mathrm{DCs}$ were not able to transfer such response (Figure 4). It is currently well established that $\mathrm{T}$ cells of Th2 phenotype are critical for asthma initiation and progression. ${ }^{18,19}$ DCs are critical for Th2 priming and necessary for the development of both acute and chronic disease phenotypes. ${ }^{39}$ We were interested to determine whether allergen-primed Sema $4 \mathrm{~A}^{-1-}$ DCs or CD4 + $\mathrm{T}$ cells are able to transfer the allergic inflammatory phenotype to naive mice followed by allergen nebulizations. It is known that OVA treatment through the airways without any adjuvant does not lead to the inflammatory response ${ }^{40,41}$ that we observed in the control allergen-nebulized WT and Sema4 $\mathrm{A}^{-/-}$ animals in this study (Figure 4). The effective transfer of the allergic disease by allergen-primed WT CD $4+\mathrm{T}$ cells has been described previously ${ }^{40,42}$ as well as the ability of the in-vivotransferred allergen-primed BM-derived WT DCs to induce asthmatic responses. ${ }^{43,44}$ However, lung DCs, most probably because of their low number and difficulties in isolation, were used only in one cell transfer study. ${ }^{45}$ This particular study has shown that two distinct subpopulations of lung DCs, namely $\mathrm{CD} 11 \mathrm{c}^{\text {high }} \mathrm{CD} 11 \mathrm{~b}^{\text {low }}$ and $\mathrm{CD} 11 \mathrm{c}^{\text {low }} \mathrm{D} 11 \mathrm{~b}^{\text {high }}$ when adoptively transferred to OVA-sensitized and challenged mice before last allergen nebulization, inhibited AHR and lung inflammation. It is noteworthy that sorted lung DCs used for our study were $\mathrm{CD} 11 \mathrm{c}+\mathrm{CD} 11 \mathrm{~b}+$ and, therefore, consisted of these two different lung DC subpopulations. Again, as noted above, sorted lung DC subpopulations were transferred to the allergen-primed and -challenged mice followed by a single challenge, ${ }^{45}$ whereas we used naive DC recipient mice.

As expected, based on the observed increased severity of allergic response in Sema $4 \mathrm{~A}^{-1-}$ mice, we found increased numbers of $\mathrm{T}$ cells in the lung tissue single-cell suspensions using a flow cytometry assay with corresponding Abs (Figure 5). However, Treg numbers were downregulated in OVAchallenged Sema $4 \mathrm{~A}^{-1-}$ mouse lungs. It is well established that CD 4 + CD25 + Foxp $3+$ Tregs downregulate Th2 response by multiple mechanisms and, vise versa, that Th 2 cytokines display a downregulatory effect on Tregs. ${ }^{46}$ Therefore, the increased allergic response in Sema $4 \mathrm{~A}^{-1-}$ mice compared with WT mice as reported here can be explained, in part, by the increased local IL-13 levels (Figure 2e) and decreased Treg numbers (Figure 5). The decreased Treg numbers in Sema $4 \mathrm{~A}^{-1-} \mathrm{CD} 4+$ T-cell preparations used in the cell transfer experiments can also explain the superior efficiency of Sema $4 \mathrm{~A}^{-1-} \mathrm{CD} 4+\mathrm{T}$ cells as compared with WT CD $4+$ T cells in transferring the allergic response to naive mice (Figure 4).

In conclusion, our previous observations on Sema4A receptor expression ${ }^{20,21}$ and our new functional data reported here suggest that a downregulatory effect of Sema4A in allergic asthma is a complex venue that cannot be simplified by its role in DC/ T-cell interaction and involves other cells, lung-resident cells, and inflammatory cells, many of which express functional receptors for Sema4A such as Plexin B1 and Plexin D1. ${ }^{20,21}$ These Plexins play important roles in cell migration ${ }^{47}$ and angiogenesis, ${ }^{14}$ both of which are critical components of asthma pathogenesis. If expressed on immune cells, ${ }^{20,21}$ these Plexins may also play a role in their activation and function.

\section{METHODS}

Mice. The generation and characterization of Sema4A-/- mice has been described in detail previously. ${ }^{15} \mathrm{C} 57 \mathrm{BL} / 6$ mice (WT) were purchased from Taconic (Hudson, NY). Mice were bred and maintained under specific pathogen-free conditions within the animal facility at University of Maryland School of Medicine. All procedures on mice were performed according to the animal protocol approved by the animal care and use committee of the University of Maryland School of Medicine. Age- and sex-matched mice were used in all experiments.

Anesthetic. Avertin in dose of 0.3 or $2 \mathrm{mg} \mathrm{kg}^{-1}$ by intraperitoneal injection was used as previously described ${ }^{32}$ to anesthetize or kill the mice, respectively.

Experimental model of allergic airway response. Mice were treated with chicken OVA (Sigma, St Louis, MO) as described previously ${ }^{20}$ (Figure 1a). Briefly, $100 \mu \mathrm{g}$ OVA per $2 \mathrm{mg}$ Alum per $200 \mu \mathrm{l}$ was delivered intraperitoneally to WT and Sema4A $\mathrm{A}^{-1-}$ mice on days 0 and 5. Control mice were injected with sterile endotoxin-free PBS/Alum. On days 12 and 14, mice received a 40-min aerosol challenge of either PBS (control animals) or 1\% (w/v) OVA using Invacare Envoy aerosol compressor (Elyria, $\mathrm{OH}$ ). At $24 \mathrm{~h}$ after last nebulization, the AHR in response to the increasing doses of methacholine was measured as an indicator of changes in the airway resistance. Mice were killed $48 \mathrm{~h}$ after the last OVA nebulization for other analyses.

Generation of BM chimeras. Bone marrows were collected and singlecell suspensions were prepared as detailed previously. ${ }^{30} \mathrm{BM}$ recipient mice were irradiated with a single dose of 500 Rad using Sheppard Mark I model 68 irradiator (San Fernando, CA). Within $6 \mathrm{~h}$ after irradiation, $8 \times 10^{6} \mathrm{BM}$ cells were injected intraperitoneally into the recipient mouse. Allergen treatment according to the defined above protocol (Figure 1a) started 6 weeks after transfer.

In vivo adoptive cell transfer. For the adoptive cell transfer experiments, the cell-donor mice were treated with OVA as described above and shown in Figure 1a. Lungs and spleens were harvested on days 16 and 19 , respectively, and processed sterilely to obtain single-cell suspensions. ${ }^{48,49}$ Lung DCs were isolated using anti-CD11c (N418) plus antiCD11b (120-000-300) beads and LS-positive selection columns (all from 
Miltenyi Biotechnology, Auburn, CA). Spleen CD4+ T cells were isolated using EasySep Negative Selection Mouse CD4 + T-cell Enrichment Kit and an EasySep column-free magnet, both from Stem Cell Technologies (Vancouver, Canada), according to the manufacturer's instructions. The purity of isolated DCs (90\%) and CD4 + T cells (95\%) was ascertained by flow cytometry analyses. Enriched cell populations were resuspended in sterile endotoxin-free PBS and $2 \times 10^{6}$ DCs per $50 \mu \mathrm{l}$ per mouse or $3 \times 10^{6} \mathrm{CD} 4+\mathrm{T}$ cells per $50 \mu \mathrm{l}$ per mouse were transferred intranasally to naive mice. The cell-recipient mice were then nebulized with $1 \%$ OVA in PBS (or PBS alone for control animals) on days 1, 2, and 3 after transfer (Figure 1b). On day 4 after transfer, BAL and serum were retrieved and lung tissues were collected.

AHR measurements. AHR measurements to methacholine challenges were performed $24 \mathrm{~h}$ after last Ag nebulization using either noninvasive (BUXCO Electronics, Wilmington, NC) or invasive (FlexiVent, SCIREQ, Montreal, Canada) techniques as previously described. ${ }^{50,51}$

Histochemistry. Core Facility at the Center for Vascular and Inflammatory Diseases was used for histochemistry (hematoxylin and eosin and PAS stains) of deparaffinized lung tissues. ${ }^{30}$

Cellular composition and cytokine/chemokine content in BALs and lung tissue lysates. BALs were performed $48 \mathrm{~h}$ after last $\mathrm{Ag}$ nebulization, cells and BALF collected, cytospin made, and cell counts performed as described earlier. ${ }^{51} \mathrm{BAL}$ and lung lysate cytokine and chemokine levels were determined using Searchlight Proteome Array (Aushon, Billerica, MA), enzyme-linked immunosorbent assay (ELISA) kits (R\&D Systems, Minneapolis, MN), and CBA kits (552364, BD Biosciences) ${ }^{30,32}$ Array and CBA data were analyzed using the ArrayVision software (Piscataway, NJ) and FlowJo plus BD CBA softwares (Ashland, OR), respectively. All ELISA plates were read on the Emax Precision Microplate reader (Molecular Devices, Sunnyvale, CA) using the manufacturer-specified wavelengths for each assay. Intact BALFs were used in the Proteome Array and ELISA. In the CBA assays, whole-lung tissue lysates ${ }^{51}$ and 5 times concentrated (Amicon Ultra 3K membranes, Millipore) BALFs were used.

Sera Ab measurements. OVA-specific IgG Ab levels in sera were determined using corresponding IgG subclass standards and AP-labeled anti-IgG Ab (Southern Biotechnology, Birmingham, $\mathrm{AL}$ ) as previously described. ${ }^{32}$ Plates were covered with an optimal concentration of $10 \mu \mathrm{g} \mathrm{ml}^{-1}$ of OVA (Sigma) defined in the previous dose-response ELISA assays. OVA-specific IgE levels were measured by ELISA (MD Bioproduct, St Paul, MN) according to the manufacturer's instruction. Total serum IgE was measured by ELISA using matching antibody pairs (R35-72 and R35-92) obtained from BD Pharmingen (San Jose, CA) as previously described. ${ }^{32}$

Proliferation assays. Cell proliferation was measured using either $[\mathrm{H}]^{3}$ incorporation assay or Quick cell proliferation assay kit (ab65473, Abcam, Cambridge, MA). Briefly, single-cell suspensions were prepared from spleens of either PBS- or OVA-challenged mice on day 5 after challenge. ${ }^{32}$ Spleen MNCs were plated to a density of $1 \times 10^{6}$ cells per $200 \mu \mathrm{l}$ in 96-well tissue culture plates (Cellstar, Greiner, Monroe, NC) and stimulated with either ConA $\left(10 \mu \mathrm{g} \mathrm{ml}^{-1}\right)$, lipopolysaccharide $\left(100 \mu \mathrm{g} \mathrm{ml}^{-1}\right.$ ), OVA (from 0.001 to $100 \mathrm{mg} \mathrm{m}^{-1}$ ), or OVA $323-339$ peptide $\left(200 \mu \mathrm{g} \mathrm{ml}^{-1}\right)$ as previously described. ${ }^{30,32,49}$ After $72 \mathrm{~h}$ of incubation, $[\mathrm{H}]^{3}$ thymidine (Perkinson-Maer, Waltham, MA) was added to the wells and plates were harvested on Packard Filtermate harvester (Packard Instruments, Meriden, CT) $24 \mathrm{~h}$ later. In a colorimetric proliferation assay, $10 \mu \mathrm{l}$ of tetrazolium salt WST-1 solution was added to each well followed by $4 \mathrm{~h}$ of further incubation. The plates were read in the ELISA plate reader at $450 \mathrm{~nm}$ with a reference wavelength of $650 \mathrm{~nm}$.

Flow cytometry. Flow cytometry of lung and spleen single-cell suspensions was performed as previously described ${ }^{30,48}$ using the
BD Biosciences (San Jose, CA) Abs for the following cell markers: I-A $^{b}$ (PE), CD4 (FITC), CD8 (PerCP), CD25 (PE), and B220 (FITC). Intracellular staining for Foxp3 was done using anti-Foxp3 (APC) Ab or rat IgG2a (APC) isotype control Ab (both from eBioscience, San Diego, CA). ${ }^{30}$ Cells gated by forward- and side-scatter parameters were analyzed using either the CELLQuest or FlowJo software (Ashland, OR) at the Flow Cytometry Facility, Center for Vascular and Inflammatory Diseases.

Statistics. Data were summarized as mean \pm s.e.m. To calculate the significance levels between the experimental groups, Student's $t$-test (Microsoft Excel) and Mann-Whitney test (Prizm-4, San Diego, CA) were performed.

\section{ACKNOWLEDGMENTS}

We thank Dr Stephen Liggett (Department of Medicine) at the University of Maryland School of Medicine for the use of the FlexiVent machine in his laboratory. We thank Dr Sun Min Lee, a Scientist at the BD Biosciences, for the calculations of CBA data using the company's CBA software. This work was supported by NIH grant R21AI076736 (to S.P.C.).

\section{DISCLOSURE}

The authors declared no conflict of interest.

(c) 2012 Society for Mucosal Immunology

\section{REFERENCES}

1. Fuhlbrigge, A.L. et al. The burden of asthma in the United States: level and distribution are dependent on interpretation of the national asthma education and prevention program guidelines. Am. J. Respir. Crit. Care Med. 166, 1044-1049 (2002).

2. Eder, W., Ege, M.J. \& Von Mutius, E. The asthma epidemic. N. Engl. J. Med. 355, 2226-2235 (2006).

3. Cohn, L., Elias, J.A. \& Chupp, G.L. Asthma: mechanisms of disease persistence and progression. Annu Rev. Immunol. 22, 789-815 (2004).

4. Borger, P., Tamm, M., Black, J.L. \& Roth, M. Asthma: is it due to an abnormal airway smooth muscle cell? Am J. Respir. Crit. Care Med. 174, 367-72 (2006).

5. An, S.S. et al. Airway smooth muscle dynamics: a common pathway of airway obstruction in asthma. Eur. Respir. J. 29, 834-860 (2007).

6. Janssen, L.J. Asthma therapy: how far have we come, why did we fail and where should we go next? Eur. Respir. J. 33, 11-20 (2009).

7. Walsh, G.M. Targeting airway inflammation: novel therapies for the treatment of asthma. Curr. Med. Chem. 13, 3105-3111 (2006).

8. Takizawa, H. Novel strategies for the treatment of asthma. Recent Pat. Inflamm. Allergy Drug Discov. 1, 13-19 (2007).

9. Kolodkin, A.L., Matthes, D.J. \& Goodman, C.S. The semaphorin genes encode a family of transmembrane and secreted growth cone guidance molecules. Cell 75, 1389-1399 (1993)

10. Kumanogoh, A. et al. Class IV semaphorin Sema4A enhances T-cell activation and interacts with Tim-2. Nature 419, 629-633 (2002)

11. Kumanogoh, A. \& Kikutani, H. Immune semaphorins: a new area of semaphorin research. J. Cell Sci 116, 3463-3470 (2003).

12. Rice, D.S. et al. Severe retinal degeneration associated with disruption of semaphorin 4A. Invest. Ophthalmol. Vis. Sci 45, 2767-2777 (2004).

13. Yukawa, K. et al. Semaphorin $4 A$ induces growth cone collapse of hippocampal neurons in a Rho/Rho-kinase-dependent manner. Int. J. Mol. Med. 16, 115-118 (2005).

14. Toyofuku, T. et al. Semaphorin-4A, an activator for T-cell-mediated immunity suppresses angiogenesis via Plexin-D1. EMBO J. 26, 1373-1384 (2007)

15. Kumanogoh, A. et al. Nonredundant roles of Sema4A in the immune system: defective $T$ cell priming and Th1/Th2 regulation in Sema4Adeficient mice. Immunity 22, 305-316 (2005).

16. Rennert, P.D. et al. T cell, Ig domain, mucin domain-2 gene-deficient mice reveal a novel mechanism for the regulation of Th2 immune responses and airway inflammation. J. Immunol. 177, 4311-4321 (2006).

17. Makino, N. et al. Involvement of Sema4A in the progression of experimental autoimmune myocarditis. FEBS Lett. 582, 3935-3940 (2008). 
18. Finkelman, F.D., Hogan, S.P., Hershey, G.K., Rothenberg, M.E. \& WillsKarp, M. Importance of cytokines in murine allergic airway disease and human asthma. J. Immunol. 184, 1663-1674 (2010).

19. Kaiko, G.E. \& Foster, P.S. New insights into the generation of Th2 immunity and potential therapeutic targets for the treatment of asthma. Curr. Opin. Allergy Clin. Immunol. 11, 39-45 (2011).

20. Smith, E.P. et al. Expression of neuroimmune semaphorins $4 A$ and $4 D$ and their receptors in the lung is enhanced by allergen and vascular endothelial growth factor. BMC Immunol. 12, 30 (2011).

21. Nkyimbeng-Takwi, E. \& Chapoval, S.P. Biology and function of neuroimmune semaphorins 4A and 4D. Immunol. Res. 50, 10-21 (2011).

22. Cohn, L., Homer, R.J., Niu, N. \& Bottomly, K. Thelper 1 cells and interferon gamma regulate allergic airway inflammation and mucus production. J. Exp. Med. 190, 1309-1318 (1999).

23. Umetsu, D.T., McIntire, J.J., Akbari, O., Macaubas, C. \& DeKruyff, R.H. Asthma: an epidemic of dysregulated immunity. Nat. Immunol. 3, 715-720 (2002).

24. Wills-Karp, M. et al. Interleukin-13: central mediator of allergic asthma. Science 282, 2258-2261 (1998).

25. Grunig, G. et al. Requirement for IL-13 independently of IL-4 in experimental asthma. Science 282, 2261-2263 (1998).

26. Zhu, Z. et al. IL-13-induced chemokine responses in the lung: role of CCR2 in the pathogenesis of IL-13-induced inflammation and remodeling. J. Immunol. 168, 2953-2962 (2002).

27. Zhu, Z. et al. Pulmonary expression of interleukin-13 causes inflammation, mucus hypersecretion, subepithelial fibrosis, physiologic abnormalities, and eotaxin production. J. Clin. Invest. 103, 779-788 (1999).

28. McKenzie, G.J., Bancroft, A., Grencis, R.K. \& McKenzie, A.N. A distinct role for interleukin-13 in Th2-cell-mediated immune responses. Curr. Biol. 8, 339-342 (1998).

29. Kelly-Welch, A.E. et al. Complex role of the IL-4 receptor alpha in a murine model of airway inflammation: expression of the IL-4 receptor alpha on nonlymphoid cells of bone marrow origin contributes to severity of inflammation. J. Immunol. 172, 4545-4555 (2004).

30. Chapoval, S.P. et al. STAT6 expression in multiple cell types mediates the cooperative development of allergic airway disease. J. Immunol. 186, 2571-2583 (2011).

31. Meurs, H., Gosens, R. \& Zaagsma, J. Airway hyperresponsiveness in asthma: lessons from in vitro model systems and animal models. Eur. Respir. J. 32, 487-502 (2008).

32. Chapoval, S.P. et al. Short ragweed allergen induces eosinophilic lung disease in HLADQ transgenic mice. J. Clin. Invest. 103, 1707-1717 (1999).

33. Crimi, E. et al. Dissociation between airway inflammation and airway hyperresponsiveness in allergic asthma. Am. J. Respir. Crit. Care Med. 157, 4-9 (1998).

34. Molet, S. et al. IL-17 is increased in asthmatic airways and induces human bronchial fibroblasts to produce cytokines. J Allergy Clin Immunol. 108, 430-438 (2001).
35. Song, C. et al. IL-17-producing alveolar macrophages mediate allergic lung inflammation related to asthma. J. Immunol. 18, 6117-6124 (2008).

36. Nembrini, C., Marsland, B.J. \& Kopf, M. IL-17-producing T cells in lung immunity and inflammation. J. Allergy Clin. Immunol. 123, 986-994 (2009).

37. Wilson, R.H. et al. Allergic sensitization through the airway primes Th17dependent neutrophilia and airway hyperresponsiveness. Am. J. Respir. Crit. Care Med. 180, 720-730 (2009).

38. Doe, C. et al. Expression of the Thelper 17-associated cytokines IL-17A and IL-17F in asthma and COPD. Chest 138, 1140-1147 (2010).

39. Lambrecht, B.N. \& Hammad, H. The role of dendritic and epithelial cells as master regulators of allergic airway inflammation. Lancet 376 , 835-843 (2010).

40. Haczku, A. et al. Adoptive transfer of allergen-specific CD4+ T cells induces airway inflammation and hyperresponsiveness in brown-Norway rats. Immunology 91, 176-185 (1997).

41. Hoyne, G.F. et al. Immunological tolerance to inhaled antigen. Am. J. Respir. Crit. Care Med. 162, S169-S174 (2000).

42. Wise, J.T., Baginski, T.J. \& Mobley, J.L. An adoptive transfer model of allergic lung inflammation in mice is mediated by CD4+CD62LlowCD25+ T cells. J. Immunol. 162, 5592-5600 (1999).

43. van Rijt, L.S. et al. In vivo depletion of lung CD11C+ dendritic cells during allergen challenge abrogates the characteristic features of asthma. J. Exp. Med. 201, 981-91 (2005).

44. Krishnamoorthy, N. et al. Activation of c-Kit in dendritic cells regulates Thelper cell differentiation and allergic asthma. Nat. Med. 14, 565-573 (2008).

45. Shao, Z., Bharadwaj, A.S., McGee, H.S., Makinde, T.O. \& Agrawal, D.K. Fms-like tyrosine kinase 3 ligand increases a lung DC subset with regulatory properties in allergic airway inflammation. J. Allergy Clin. Immunol. 123, 917-924 (2009).

46. Chapoval, S., Dasgupta, P., Dorsey, N.J. \& Keegan, A.D. Regulation of the Thelper cell type 2 (Th2)/T regulatory cell (Treg) balance by IL-4 and STAT6. J. Leukoc. Biol. 87, 1011-1018 (2010).

47. Choi, Y.I. et al. PlexinD1 glycoprotein controls migration of positively selected thymocytes into the medulla. Immunity 29, 888-898 (2008).

48. Chapoval, S.P. et al. Lung vascular endothelial growth factor expression induces local myeloid dendritic cell activation. Clin. Immunol. 132, 371-384 (2009).

49. Chapoval, S.P. et al. HLA-DQ6 and HLA-DQ8 transgenic mice respond to ragweed allergens and recognize a distinct set of epitopes on short and giant ragweed group 5 antigens. J. Immunol. 161, 2032-2037 (1998).

50. Deshpande, D.A. et al. Bitter taste receptors on airway smooth muscle bronchodilate by localized calcium signaling and reverse obstruction. Nat. Med. 16, 1299-1304 (2010).

51. Chapoval, S.P. et al. Inhibition of NF-kappaB activation reduces the tissue effects of transgenic IL-13. J. Immunol. 179, 7030-7041 (2007). 